\title{
Work on weapons adds to public distrust of science
}

\section{Academics need to remain independent and remember their ethical obligations.}

Sir - The partial transparency concerning the technology needed to retain Britain's nuclear weapons, represented by the Feature "Science of nuclear warheads" (Nature 415, 853-857; 2002) by Keith O'Nions et al., is to be welcomed. Yet it is disappointing that the authors do not discuss the alternative of decommissioning and destroying such weapons - required if Britain is to adhere to international law and to the agreements it has signed, such as the Nuclear Non-Proliferation Treaty.

The apparent subordination of science to government is one cause of current public distrust of scientists and of student reluctance to embark upon scientific careers. Views such as those in the article concerning nuclear-warhead science can only add to this alienation.

O'Nions et al. call for new appointees to develop "a deeper theoretical and experimental understanding" of the science needed to underwrite "the safety and performance of the ageing Trident stockpile". But they do not explain what "performance" means in this context, and could perhaps agree that in a slightly modified political climate, safety could be assured by dismantling and destroying warheads.

The problems of doing this, and the verification needed, may well require the temporary involvement of high-calibre scientists and engineers. Whether we can or should hire them to maintain the threats is doubtful, and few able students interested in fundamental science are likely to see the latter as a desirable career.

The US National Ignition Facility and the supercomputing devices discussed in the Feature are means by which weapons of mass destruction can be developed and partially tested without breaching the letter of the Comprehensive Test Ban Treaty. O'Nions et al. describe a retention programme that, they say, would not only recruit high-calibre staff but "work with British academics and industry" to retain indefinitely "the reliability and safety of Britain's independent nuclear warhead".

This ignores the need for the "British academic community" (if there is such a thing) to stay independent of government pressure; to consider the ethical dimension of their collaborations; to continue open international links, including with the former Soviet Union and politically unstable parts of the developing world; and to advise students on careers with both intellectual challenge and moral probity. Peter Nicholls

Chair, Abolition 2000 UK, and Department of Biological Sciences, University of Essex, Colchester, Essex CO4 3SQ, UK

\section{Mutation not universally linked with diabetes}

Sir-Pierre Maechler and Claes B. Wollheim ${ }^{1}$ in their interesting Insight Review Article on mitochondrial function in normal and diabetic $\beta$-cells show diabetes-associated mutations in the human mitochondrial genome in their Fig. 1. One of these mutations is G3316A in the ND1 gene (references cited in ref. 1).

Until recently, this mutation had been reported only in a Japanese population. Since then, other independent studies ${ }^{2,3}$ have not found this association between G3316A and diabetes in Chinese people or in another Japanese population ${ }^{4}$.

Because about $4 \%$ of China's 1.2 billion people carry this mutation ${ }^{2}$, it is important that the polymorphism G3316A is not regarded as diabetes-associated outside the Japanese population reported in ref. 1. Ching-Wan Lam

Department of Chemical Pathology, The Chinese University of Hong Kong, Hong Kong, China

1. Maechler, P. \& Wollheim, C. B. Nature 414, 807-812 (2001).

2. Lam, C. W. et al. J. Med. Genet. 38, E10 (2001).

3. Ji, L., Hou, X. \& Han, X. Diabetes Res. Clin. Pract. 54, Suppl. 2, S35-S38 (2001)

4. Matsuura, N. et al. J. Pediatr. Endocrinol. Metab. 12, 27-30 (1999).

\section{Single-locus studies}

Sir - Neil Risch et al. in Correspondence ${ }^{1}$ state that our paper ${ }^{2}$ on the genetic relatedness of Palestinians and Jews lacked scientific merit because its conclusions are based on data reported for a single-locus genetic marker (HLA-DRB1). Although the use of single-locus markers can lead to misleading results, single-locus studies, whether using HLA or other markers, are common in this field and are regularly published in the specialist literature.

In papers reporting data on a single locus, it is important not to take anomalous results at face value but to interpret them in the light of other types of data, such as historical, anthropological and linguistic data, as well as testing them using other genetic markers (see, for example, ref. 3 ). As we stated in ref. 2, we are currently investigating the populations reported in our paper using other markers.

Antonio Arnaiz-Villena, Eduardo GomezCasado, Jorge Martinez-Laso

Department of Immunology (Microbiology), Faculty of Medicine, Universidad Complutense, 28040 Madrid, Spain

\section{e-mail:aav@efd.net}

1. Risch, N., Piazza, A. \& Cavalli-Sforza, L. L. Nature 415, 115 (2002). 2. Arnaiz-Villena, A. et al. Hum. Immunol. 62, 889-900 (2001).

3. Dork, T. et al. Am. J. Hum. Genet. 63, 656-662 (1998).

\section{Call for Elan to publish Alzheimer's trial details}

Sir - One potential route for therapy for Alzheimer's disease involves the immunization of patients against the amyloid- $\beta$ peptide, the major proteinaceous component that characterizes plaques in the brains of patients with this disease. Resulting from earlier research on mice, published in Nature ${ }^{1-3}$,
Elan Pharmaceuticals recently began clinical trials of a vaccine, AN-1792, based on this approach. In January, four patients in this trial developed inflammation of the central nervous system, and Elan suspended the trial pending further investigation ${ }^{4}$. By March, the number of patients in this trial who had symptoms resembling encephalitis and meningitis was reported to have increased to 15 , and Elan has permanently withdrawn the AN-1792 vaccine from human trials ${ }^{5}$.

It is not clear precisely what caused the inflammation in these patients, as Elan has released few details of their medical condition. Elan is under no obligation to report the results of the AN-1792 trials, and may well not wish to lose its perceived scientific or commercial advantage.

Nonetheless, detailed information of the conditions developed by these patients is of profound interest to the scientific community as well as society at large. We therefore urge Elan to publish details from their study as quickly as possible, so that any foreseeable side-effects can be avoided in future trials.

Glenda M. Bishop ${ }^{\star}$, Stephen R. Robinson $\dagger$, Mark A. Smith ${ }^{\star}$, George Perry ${ }^{\star}$ \& Craig S. Atwood ${ }^{\star}$

${ }^{\star}$ Institute of Pathology, Case Western Reserve University, Cleveland, Ohio 44106, USA

$\uparrow$ School of Psychology, Psychiatry and Psychological Medicine, Monash University, Clayton, Victoria

3800, Australia

1. Schenk, D. et al. Nature 400, 173-177 (1999).

2. Janus, C. et al. Nature 408, 979-982 (2000).

3. Morgan, D. et al. Nature 408, 982-985 (2000).

4. Check, E. Nature 415, 462 (2002).

5. Weiss, R. Washington Post A03 (2 March 2002) 